\title{
Concerted circadian oscillations in transcript levels of nineteen Lha/b (cab) genes in Lycopersicon esculentum (tomato)
}

\author{
Jan-Wolfhard Kellmann ${ }^{1}$ *, Nicole Merforth ${ }^{1}$, Michael Wiese ${ }^{1}$, Eran Pichersky ${ }^{2}$ \\ and Birgit Piechulla ${ }^{1}$ \\ 1 Institut für Biochemie der Pflanze, Untere Karspüle 2, W-3400 Göttingen, FRG \\ ${ }^{2}$ University of Michigan, Department of Biology, Ann Arbor, MI 48109, USA
}

Received August 10,1992 / Accepted September 28, 1992

\begin{abstract}
Summary. Steady-state mRNA levels of nineteen members of the $L h a / b$ ( $c a b)$ gene family of Lycopersicon esculentum, encoding nine different types of light-harvesting complex (LHC) polypeptides, were determined by primer extension analysis. Each Lha/b gene is expressed and individual mRNAs accumulate to distinct levels. The relative contribution of each $L h a / b$ mRNA to the total $L h a / b$ mRNA levels is very similar in different green organs (leaves, stems, fruits, sepals) and after light treatment of etiolated seedlings. Detailed analysis of $L$ ha $/ b \mathrm{mRNA}$ accumulation in leaves under light/dark conditions, continuous darkness and continuous light revealed diurnal and circadian oscillations of $L h a / b$ mRNAs for all genes. Only minor instances of divergence from a general expression pattern are apparent. Together these results indicate a concerted expression of all genes, suggesting that similar or identical molecular mechanisms and signal transduction chain control the expression of all Lha/b genes.
\end{abstract}

Key words: Tomato (Lycopersicon esculentum) - Lha/b gene expression - Light harvesting complex (LHC) proteins - Gene family - Circadian rhythm

\section{Introduction}

The group of evolutionary and structurally related genes known as $c a b$ or $L h a / b$ (Green et al. 1991; Jansson et al. 1992), encode the chlorophyll $a / b$-binding polypeptides of the light harvesting systems in plant thylakoids. In tomato, nineteen $L h a / b$ genes have so far been characterized (Green et al. 1991), coding for proteins that belong to the light harvesting complex LHCI, associated with photosystem I (PSI), and the light harvesting complexes of LHCII, CP29, and CP24, all associated with PSII.

\footnotetext{
* Present address: Max-Planck-Institut für Züchtigungsforschung, Carl-von-Linne-Weg 10, W-5000 Köln, FRG

Correspondence to: B. Piechulla
}

At least nine different types of Lha/b genes have been identified so far, whose products display variations resulting from sequence similarities which range from 40 to $85 \%$. In tomato, about half of the different types of LHC polypeptides are encoded by more than one gene, and the genes are located in many unlinked loci on most of the tomato chromosomes, with some clustering of genes encoding the same type of polypeptide.

The expression of the $L h a / b$ genes in higher plant species has been previously investigated. Endogenous (organ and tissue specificity, developmental program and circadian clock, Kuhlemeier et al. 1987; Meyer et al. 1989, Kay and Millar 1992) and exogenous (light and temperature, Kuhlemeier et al. 1987; Piechulla and Riesselmann 1990) signals were shown to play important roles in determining the accumulation levels of $L h a / b$ mRNA in etiolated seedlings and also in adult plants. However in most of the previous work, only one kind of gene probe, the $L h b 1$ gene, was used and therefore the results represent primarily the expression pattern of the genes encoding the type I LHC protein of photosystem II. In addition, in only a few investigations were gene-specific probes used to identify individual $L h b 1$ transcripts (Sheen and Bogorad 1986; Kellmann et al. 1990; Millar and Kay 1991) and to our knowledge only in three cases were Lha mRNAs, which encode LHCI polypeptides, discriminated from $L h b$ mRNAs (Stayton et al. 1989; Tavladoraki and Argyroudi-Akoyunoglou 1989; Wehmeyer et al. 1990).

At this time it is not known to what extent each individual $L h a / b$ gene contributes to the total amount of the $L h a / b$ mRNA levels present at specific times during the day and in specific organs or tissues of tomato or other plant species. Since different Lha/b genes encode specific types of LHC proteins, which may have distinct functions or locations within the thylakoid membrane, it was of interest to determine the individual $L h a / b$ mRNA levels in various green plant organs (leaves, stems, green fruits and sepals) and also in etiolated seedlings illuminated with white light or red and far-red light pulses. 
However, the sequence similarity between the $L h a / b$ genes complicates the detection of individual expression patterns in conventional dot or Northern blot hybridization experiments. Cross-hybridization in Northern blots is difficult to avoid and often difficult to detect since the lengths of the $L h a / b$ gene transcripts are very similar. Therefore the primer extension technique was chosen to determine the steady-state mRNA levels of individual members of a gene family (Dean et al. 1987; Stayton et al. 1989; Kellmann et al. 1990). We applied this method to detect individual $L h a / b$ mRNAs of the well-characterized tomato $L h a / b$ gene family. The individual $L h a / b$ mRNAs are identified by their specific transcript length based on the binding position of the oligonucleotide (Piechulla et al. 1991). Furthermore, the defined experimental conditions allow precise quantitation in $\mathrm{fmol} / \mathrm{mg}$ total RNA of each individual Lha/b mRNA.

\section{Materials and methods}

Plant growth conditions and RNA isolation. Leaves were harvested from tomato plants at 38 days (Figs. 4 and 5) and 42 days (Fig. 6) (Lycopersicon esculentum Mill. VFNT LA 1221). Plants were grown in a growth chamber on clay beads, watered with tap water and kept under a $12 \mathrm{~h}$ light $/ 12 \mathrm{~h}$ dark regime $\left(300 \mu \mathrm{mol} / \mathrm{m}^{2}\right.$ per $\mathrm{s}$, Osram Universal Weiss, L $65 \mathrm{~W} / 25$ ) and at constant temperature $\left(24^{\circ} \mathrm{C}\right)$. Leaves were harvested at the indicated time points. In addition, leaves were harvested at 1.30 p.m. from 50 -day-old plants grown in the greenhouse at the University of Göttingen (Fig. 2). Stems, i.e. all internodal segments from the top down to the primary leaves, were harvested from 56- and 69-day-old tomato plants. Green fruits $1-1.5 \mathrm{~cm}$ in diameter (approximately 10 days after pollination) were obtained from 58- and 73-day-old plants. Sepals were harvested from flowering 61- and 69-day-old tomato plants. Stems, green fruits and sepals were harvested at 12.00 p.m. from plants grown in the greenhouse under natural light conditions.

Etiolated tomato seedlings grew in growth chambers at constant temperature $\left(23^{\circ} \mathrm{C}\right)$ for 7 days and were illuminated with white light $(6.00$ a.m. to 6.00 p.m., $290 \mu \mathrm{mol} / \mathrm{m}^{2}$ per s, Osram Lumilux $58 \mathrm{~W}$, colour 31 ; Fig. 3 and Table 2). For the phytochrome experiment the tomato seedlings were grown in darkness for 10 days $\left(25^{\circ} \mathrm{C}\right)$ and treated with red and far-red pulses as described by Mohr et al. (1979); $10 \mathrm{~min}$ red light $\left(\lambda_{\max }=\right.$ $658 \mathrm{~nm}, 3.8 \mu \mathrm{mol} / \mathrm{m}^{2}$ per s), $10 \mathrm{~min}$ far-red light $\left(\lambda_{\max }=\right.$ $730 \mathrm{~nm}, 18 \mu \mathrm{mol} / \mathrm{m}^{2}$ per s) and $10 \mathrm{~min}$ red light followed by $10 \mathrm{~min}$ far-red light. Isolation and purification of the RNA from these tissues was performed as described elsewhere (Kellmann et al. 1990).

Determination of steady-state Lha/b mRNA levels. Primer extension with specific oligonucleotides were carried out to determine the steady-state mRNA levels expressed by individual $L h a / b$ genes (Table 1 ). Oligonucleotides were labelled at the $5^{\prime}$ end and a $0.1 \mathrm{pmol}$ aliquot of the primer was spotted onto a nylon membrane to determine the specific radioactivity (Cerenkov counting). Annealing of the oligonucleotide to the specific $L h a / b$ mRNA was optimized by varying the potassium chloride concentration and the hybridization temperature (Piechulla et al. 1991). The experiments described here were performed with 0.3 pmol oligonucleotide coprecipitated with $50 \mu \mathrm{g}$ of total RNA. The relative levels

Table 1. Oligonucleotide sequences complementary to Lha/b genes of Lycopersicon esculentum and resulting length of primer-extended fragments

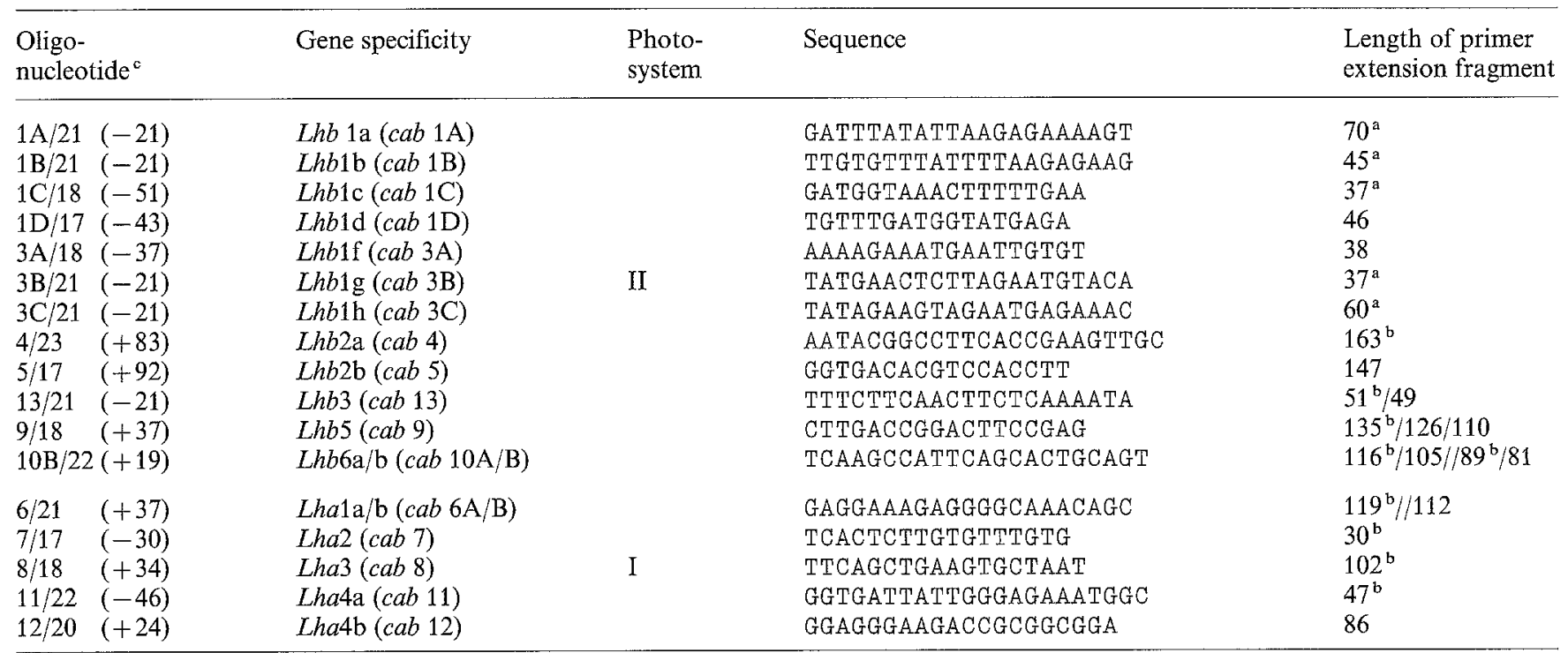

a Transcription start point additionally verified by $\mathrm{S} 1$ nuclease digestion experiment

b Transcription start point additionally verified through cDNA sequencing

c Oligonucleotide assignment indicates: gene specificity/length of oligo (binding position; A of ATG set as +1 , as in Piechulla et al. 1991) 

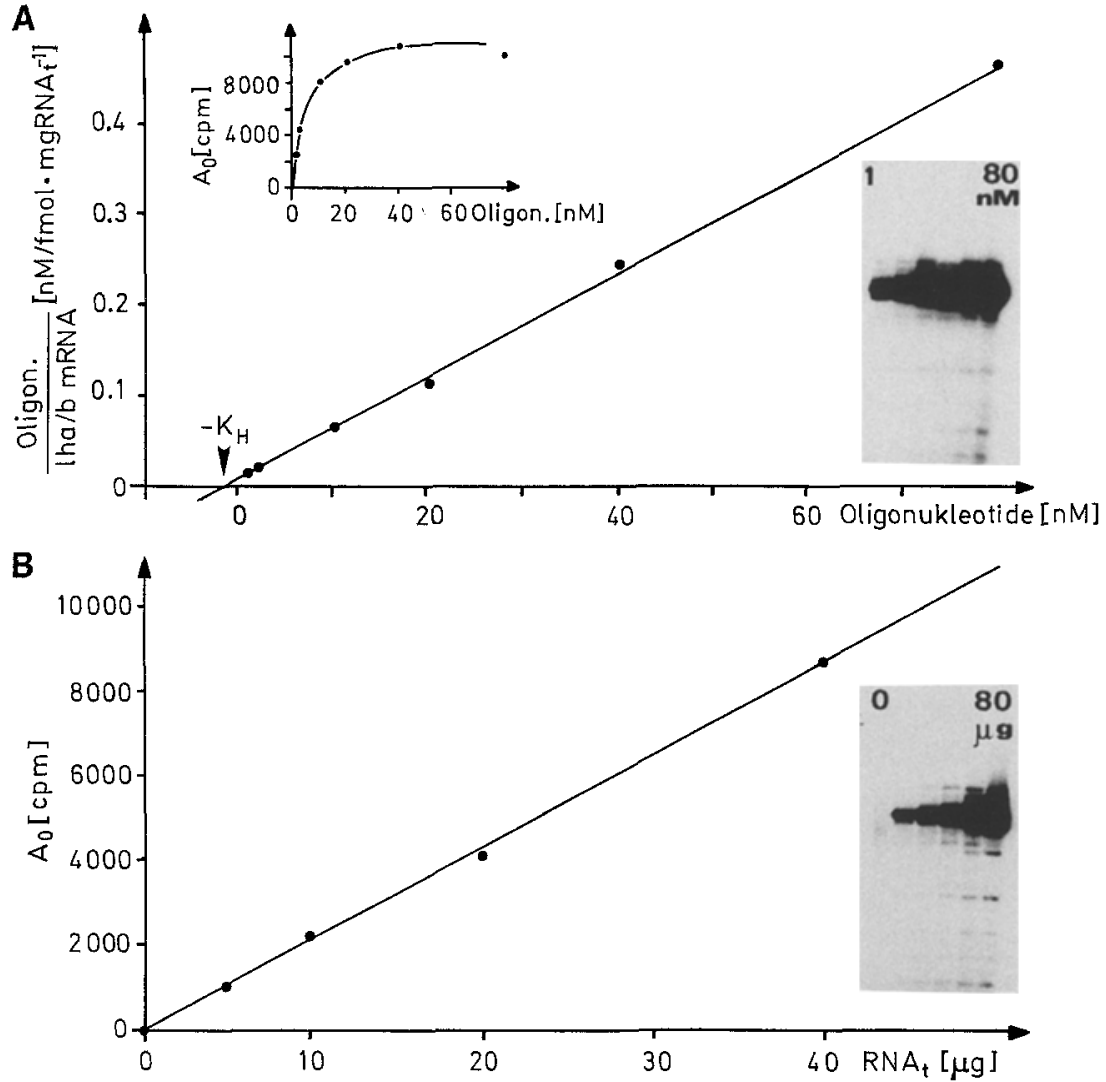

Fig. 1A, B. Kinetic studies of the primer extension reaction. A Determination of the oligonucleotide amount that results in a half-maxium signal from the primer-extended fragment (ss DNA; $\left.K_{\mathrm{H}}\right) ; 40 \mu \mathrm{g}$ total RNA $\left(\mathrm{RNA}_{\mathrm{t}}\right.$ ) was coprecipitated with increasing amounts of the oligonucleotide 1B/21 $\bullet \bullet)$. The data are presented in a 'Hanes plot' and $K_{\mathrm{H}}$ was determined to be $2 \mathrm{nM}$. Insert: Relationship between oligonucleotide concentration (substrate) and level of primer-extended fragment (product) in a primer extension assay. Specific radioactivity of the primer extended fragments $\left(\mathrm{A}_{0}\right)$ was normalized to the day of the kinase reaction.

B Relationship of total RNA (substrate) to the primer-extended fragment (product). Radioactivity of the ssDNA was normalized to that on the day of the kinase reaction $\left(A_{0}\right)$ of the individual $L h a / b$ mRNAs were determined by isolating the respective single-stranded DNA fragments from the gel and subjecting them to Cerenkov counting. Since the primers were $5^{\prime}$ end-labelled, 1 mol extended primer (ssDNA fragment) equals 1 mol Lha/b mRNA. The molar amounts of steady-state mRNAs of individual $L h a / b$ genes (in fmol $L h a / b$ mRNA/mg total RNA) was calculated as follows.

steady-state $\mathrm{mRNA}$ level $=$

primer $(\mathrm{mol}) \times$ radioactivity of ssDNA $\left(\mathrm{A}_{0}\right)(\mathrm{cpm})$

radioactivity primer $\left(\mathrm{A}_{0}\right) \times \mathrm{RNA}$ total $(\mathrm{mg})$

Where $A_{0}$ is measured radioactivity normalized to the day of the kinase reaction.

The experimental conditions of the primer extension analysis were optimized as follows. Firstly, an optimal salt concentration and annealing temperature was determined for each oligonucleotide/Lha/b mRNA combination (Piechulla et al. 1991). Secondly, the oligonucleotide was added in excess over the $L h a / b$ mRNA concentration. The correct concentration of the oligonucleotide was determined by increasing the amounts of the $5^{\prime}$ endlabelled oligonucleotide $(1-80 \mathrm{nM})$, coprecipitating it with $40 \mu \mathrm{g}$ total RNA, and measuring the amounts of radioactively labelled primer-extended ssDNA fragments. The radioactivity of these ssDNA fragments measured in the different experiments was normalized to the day of the kinase reaction $\left(\mathrm{A}_{0}\right)$. The radioactivity of primer extension product $\left(\mathrm{A}_{0}\right)$ was plotted versus the concentration of oligonucleotide $(\mathrm{nM})$ and a saturation curve was obtained (Fig. 1 A, insert). The data were converted into an Hanes plot and the amount of $2 \mathrm{nM}$ oligonucleotide $\left(K_{H}\right)$ was calculated to produce a half-maximum signal (Fig. 1 A). At least tenfold excess of oligonucleotide over $K_{\mathrm{H}}$ was used in the primer extension experiment (i.e. $0.2-0.3 \mathrm{pmol}$ end-labelled oligonucleotide in $10 \mu$ l annealing assay). The method assumes that the relationship between increasing amounts of total RNA $(5-80 \mu \mathrm{g})$ and increasing amounts of primer extension product is linear. The linear relationship of these two parameters is depicted in Fig. 1B. The results of these control experiments demonstrate that the primer extension analysis is a useful and reliable technique for quantitation of specific $L h a / b$ transcripts.

\section{Results}

Expression of nineteen Lha/b genes in various plant organs

Using the primer extension analysis the $L h a / b$ mRNA levels were determined in leaves, stems, young green fruits and sepals (all samples were harvested at noon; Table 2A). The accumulation levels are expressed as the percentage contribution of individual $L h a / b$ mRNAs to the total amount of $L h a / b$ mRNA present in the particular organ (Fig. 2). High expression levels are obtained for $L h b 1 b, 1 f, 1 g, 2 a(c a b 1 B, 3 A, 3 B, 4)$ and Lha2 ( $c a b 7)$, while the contribution of the other $L h a / b$ 
Table 2 A. Determination of steady-state $L h a / b$ mRNA levels (fmol/mg RNA $\mathrm{m}_{\text {total }}$ ) in different organs and cotyledons of etiolated seedlings

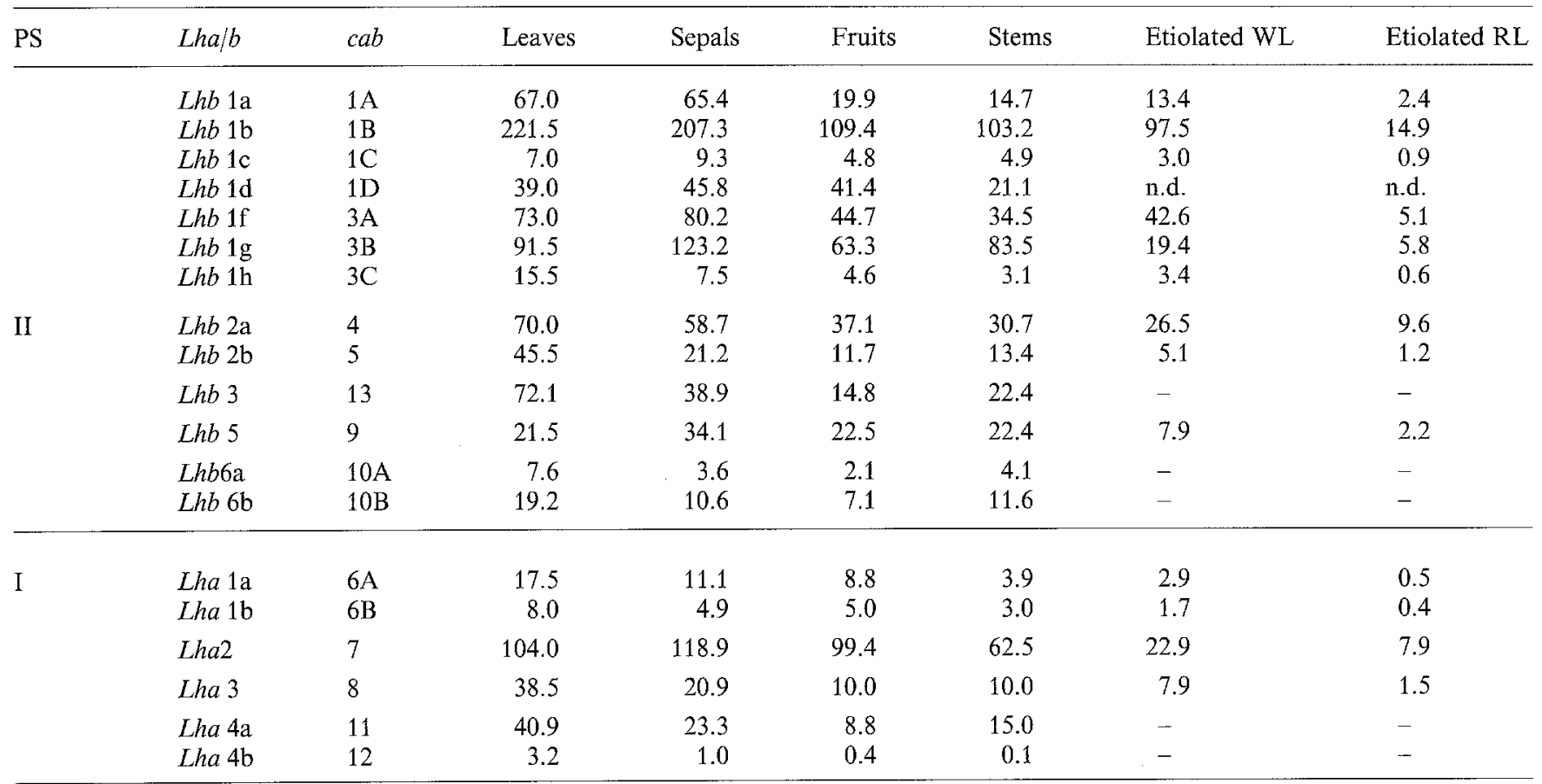

PS, photosystem

Maximum deviation is presented as error bars in Fig. 2

n.d., not detectable; WL, white light; RL, red light

Table 2B. Summary of total Lha/b mRNA levels (fmol/mg RNA $_{\text {total }}$ ) in different organs and cotyledons of etiolated seedlings

Tissue and light Total $L h a / b$ expression level conditions at 12.00 a.m.

\begin{tabular}{lr}
\hline Leaves, daylight & 962.5 \\
Sepals, daylight & 885.9 \\
Fruits, daylight & 515.8 \\
Stems, daylight & 464.1 \\
Etiolated seedlings, & \\
6 h in white light & \\
Etiolated seedlings, $_{4}$ & 254.1 \\
h in white light & \\
4 h after red light pulse $^{\mathrm{a}}$ & 171.3 \\
$4 \mathrm{~h}$ after far-red light pulse & \\
$4 \mathrm{~h}^{\mathrm{a}}$ after red/far-red light pulse & \\
\end{tabular}

a RNA levels of fourteen $L h a / b$ genes are summarized ( $c a b$ 1$c a b$ 9)

mRNAs to the total amount of $L h a / b$ mRNA is very low. The comparisons of the levels of transcripts show similar Lha/b mRNA accumulation patterns in the different plant organs (Fig. 2).

In contrast to the similarity of the Lha/b mRNA accumulation patterns, the total amount of $L h a / b \mathrm{mRNA}$ per $m g$ total RNA varies in the different plant organs (Table 2B). Highest levels of $L h a / b$ transcripts per $\mathrm{mg}$ total RNA were determined in leaves, followed by sepals (962.5 and $885.9 \mathrm{fmol} L h a / b \mathrm{mRNA}$ per mg total RNA, respectively). Approximately $50 \%$ of this amount is pres- ent in young green tomato fruits and stems (respectively, 515.8 and $464.1 \mathrm{fmol} L h a / b$ mRNA per mg total RNA). Together these results indicate that the sum of $L h a / b$ mRNA levels per total amount of RNA is different in the different organs, suggesting that this parameter is organ dependent, while the distribution or composition pattern of $L h a / b$ mRNAs is organ independent.

\section{Transcript accumulation in white, red and far-red illuminated, etiolated seedlings}

The expression of the individual Lhal $b$ mRNAs was determined in etiolated seedlings illuminated with white light. The cotyledons of such seedlings were harvested every $2 \mathrm{~h}$. All Lha/b mRNAs were measurable with the primer extension technique $4 \mathrm{~h}$ after illumination, and most of the transcripts were already present $2 \mathrm{~h}$ after the onset of light (Fig. 3). The relative distribution pattern of the Lha/b transcripts examined is very similar to that observed in adult leaves, sepals, green fruits and stems (Fig. 2). Besides the similarity of the quantitative distribution of $L h a / b$ mRNAs the features of diurnal variation in $L h a / b$ transcripts were investigated in illuminated seedlings (Fig. 3). Increasing levels of the $L h a / b$ mRNAs were obtained after the transition from darkness to light, reaching a maximum about $6 \mathrm{~h}$ after the onset of illumination, and decreasing levels were measured thereafter. At midnight, the transcript levels were below the detection level, with the exception of Lha2, 3 and $\operatorname{Lhb5}$ ( $c a b$ 7, 8 and 9). 


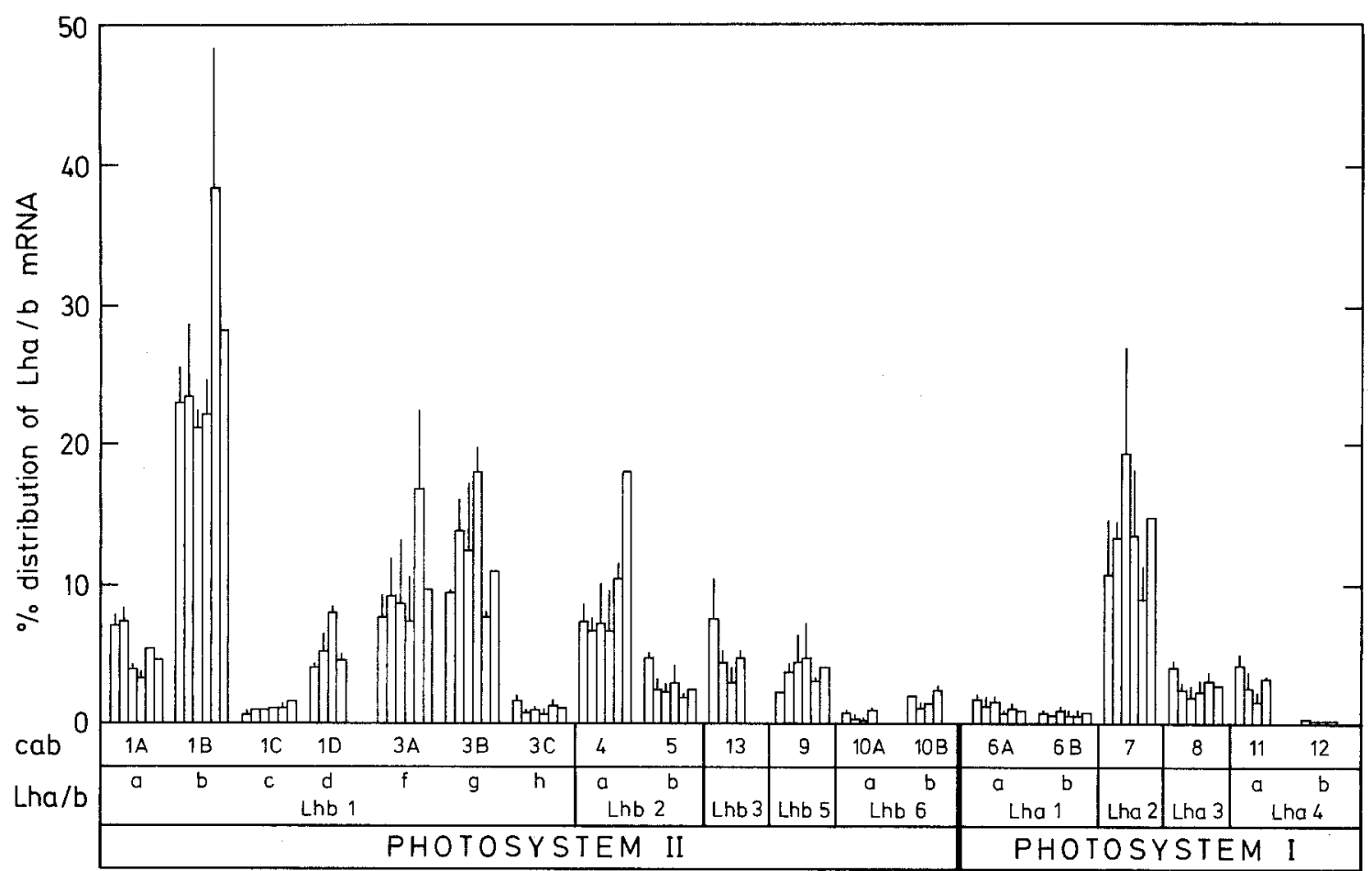

Fig. 2. Distribution patterns of steady-state mRNA levels of individual Lha/b genes from Lycopersion esculentum. Transcript levels were determined in leaves, stems, sepals and young green fruits (columns 1-4; left to right) harvested around noon. Calculation of relative distribution was based on mRNA levels of nineteen $L h a / b$ genes $(c a b 1-13)$. Cotyledons of etiolated seedlings were harvested $6 \mathrm{~h}$ after the onset of white light and $4 \mathrm{~h}$ after a $10 \mathrm{~min}$

red light pulse (columns 5 and 6). Calculation of relative distribution was based on mRNA levels of fourteen Lha/b genes (cab1-9). The levels of the individual $L h a / b$ mRNAs were determined by primer extension and the relative portion of the total $L h a / b$ mRNA was calculated. Error bars represent maximum deviation calculated from two or three experiments
The role of phytochrome in the expression of the individual $L h a / b$ genes was examined by exposing etiolated seedlings to $10 \mathrm{~min}$ red light, far-red light or red/ far-red light, respectively. The cotyledons were harvested $2,4,9,16$ and $24 \mathrm{~h}$ after the application of the light pulses. The mRNA of each $L h a / b$ gene was already detectable $2 \mathrm{~h}$ after the red light pulse. The mRNA levels increased to high levels $4 \mathrm{~h}$ after the light pulse and decreased thereafter, indicating diurnal expression (data not shown). A similar pattern, but with reduced amplitudes, appeared in far-red and red/far-red illuminated cotyledons of etiolated seedlings. The level of total $L h a / b$ mRNA after far-red illumination reached $56 \%$ compared to the level in red light-treated seedlings, while the far-red pulse given immediately after the red light pulse reduced the total $L h a / b$ mRNA level only to $84 \%$ (Table 2B). The distribution pattern of the individual Lha/b mRNAs $4 \mathrm{~h}$ after the red light pulse is similar to the pattern observed after white light illumination or in adult leaves (Fig. 2). The characteristic diurnal expression patterns found for each individual $L h a / b$ gene after different light treatments suggest that all Lha/b genes are most probably controlled by the same mechanism which is already operative in young plant material.

Despite the similarity in distribution patterns of the individual $L h a / b$ mRNAs differences were observed with respect to the total amounts of $L h a / b$ mRNA found in etiolated seedlings treated with different light regimes
(Table 2B). Etiolated seedlings illuminated with white light for $4 \mathrm{~h}$ reach $171.3 \mathrm{fmol}$ per mg total RNA and $6 \mathrm{~h}$ in white light induces a level of $254.1 \mathrm{fmol}$ per $\mathrm{mg}$ total RNA (based on fourteen genes, $c a b$ 1-9). Pulses of $10 \mathrm{~min}$ red, far-red or red/far-red light resulted in total $L$ hal $b$ mRNA levels between 30 and $53 \mathrm{fmol}$ per $\mathrm{mg}$ total RNA $4 \mathrm{~h}$ after the treatment (based on fourteen genes, $c a b$ 1-9). Together these results indicate that $L h a /$ $b$ mRNA expression in etiolated seedlings is dependent on light intensity and light quality.

\section{Circadian expression patterns of Lha/b transcripts}

Previous studies have shown that total Lha/b mRNA levels oscillate in a diurnal and circadian fashion; however, individual genes were not examined. The results of our primer extension analysis of tomato $L h a / b$ genes during the course of $72 \mathrm{~h}$ are presented in Figs. 4 and 5. Under normal light/dark conditions the mRNA from each $L h a / b$ gene exhibits a typical diurnal expression pattern with increasing transcript levels after the transition from darkness to light, reaching a maximum around noon and decreasing thereafter. It should be noted that increasing mRNA levels from Lha2 (cab 7), Lhb1a, 1d, $2 a$ and $3(c a b 1 A, 1 D, 4,13)$ are already detectable prior to the dark/light transition. This may be due to the abundant expression of these genes. A quantitative presenta- 


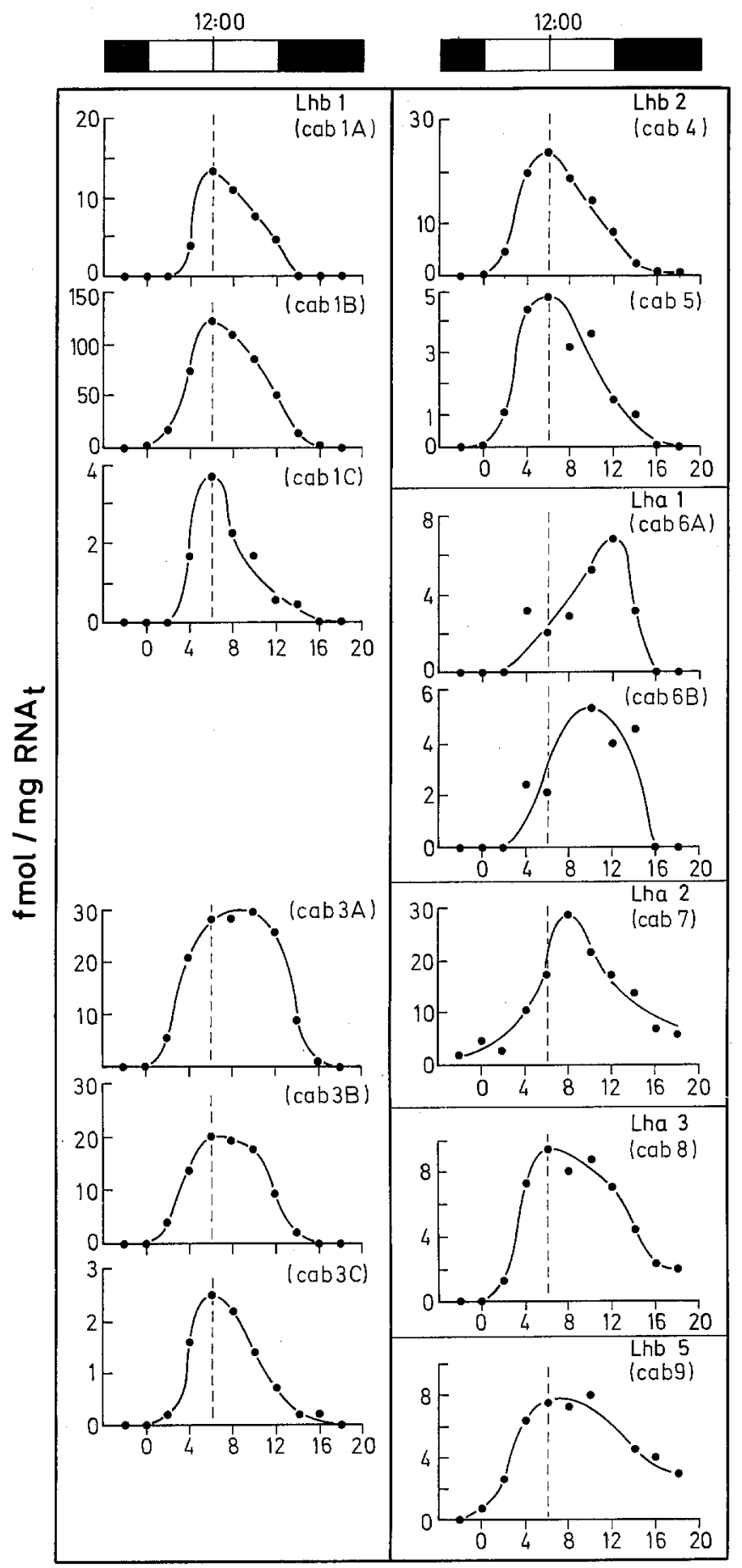

hours

Fig. 3. Diurnal rhythms of steady-state transcript levels for individual $L h a / b$ genes in illuminated, etiolated secdlings of $L$. esculentum. Seven-day-old seedlings were illuminated for $12 \mathrm{~h}$ with white light. Steady-state mRNA levels of fourteen individual Lha/b genes (cab1-9) were calculated based on the primer extension analysis. The amount of individual $L h a / b$ mRNA is given in $\mathrm{fmol} / \mathrm{mg}$ total RNA; the time axis presents the 'Zeitgeber' time. The light/dark regime is presented as open and filled bars, respectively. Genes encoding one type of light harvesting complex (LHC) protein are grouped together in sections

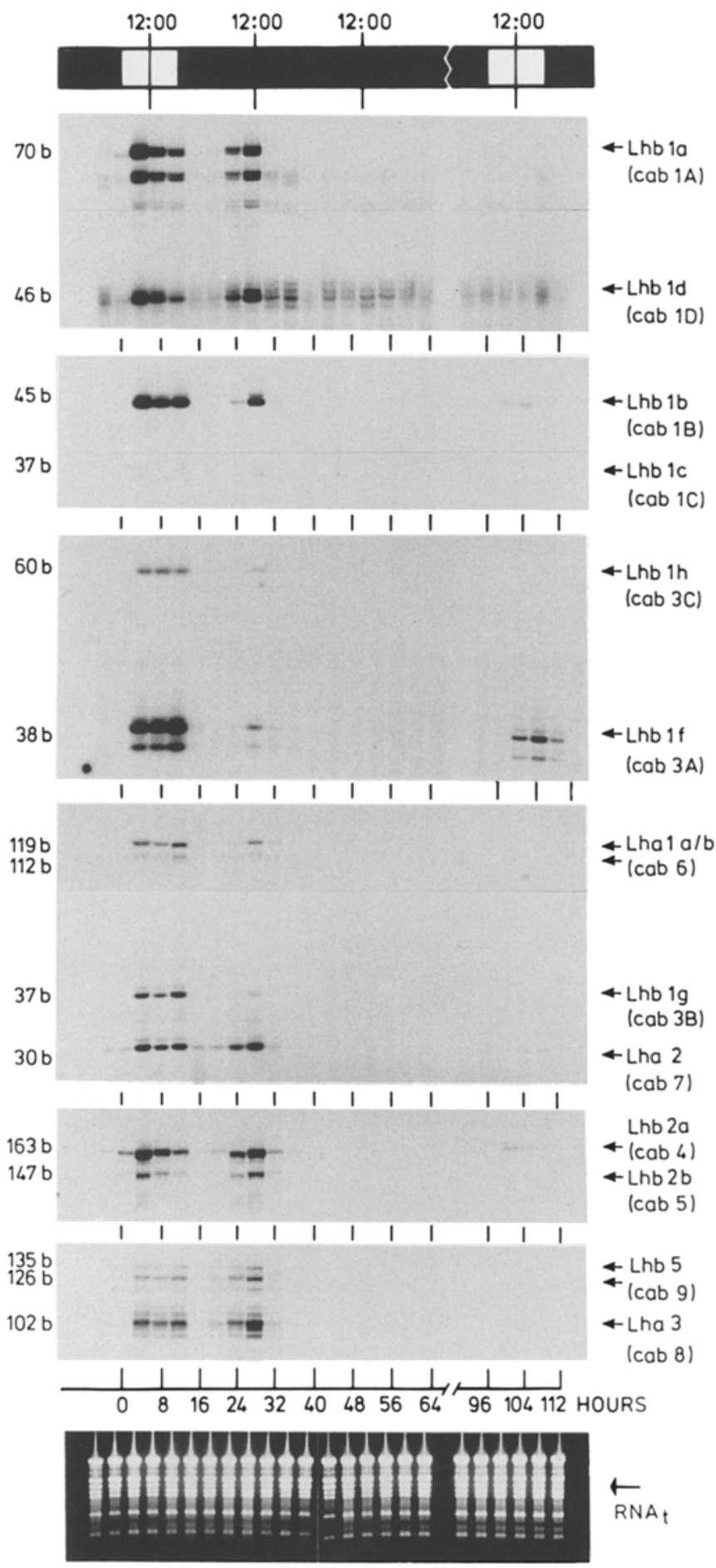

Fig. 4. Autoradiograms of the primer extension analysis of individual Lha/b genes of $L$. esculentum. The steady-state mRNA levels of fourteen $L h a / b$ genes were determined at several time points in light/dark and continuous dark conditions. At each time point $50 \mu \mathrm{g}$ of total RNA isolated from leaves of adult plants was coprecipitated with 0.3 pmol $5^{\prime}$ end-labelled oligonucleotide. Primers with similar optimal hybridization conditions and that reveal primer extended products of different lengths were assayed simultanously in a single reaction. The lengths (in b) of the primerextended fragments are indicated as well as the particular gene product. Zeitgeber time is presented together with the periods of light/dark transition: the time point of the first dark/light transition was set as zero. Lower panel: total RNA was extracted from leaves, separated on a denaturing agarose gel $(7.5 \mu \mathrm{g}$ per lane) and stained with ethidium bromide 


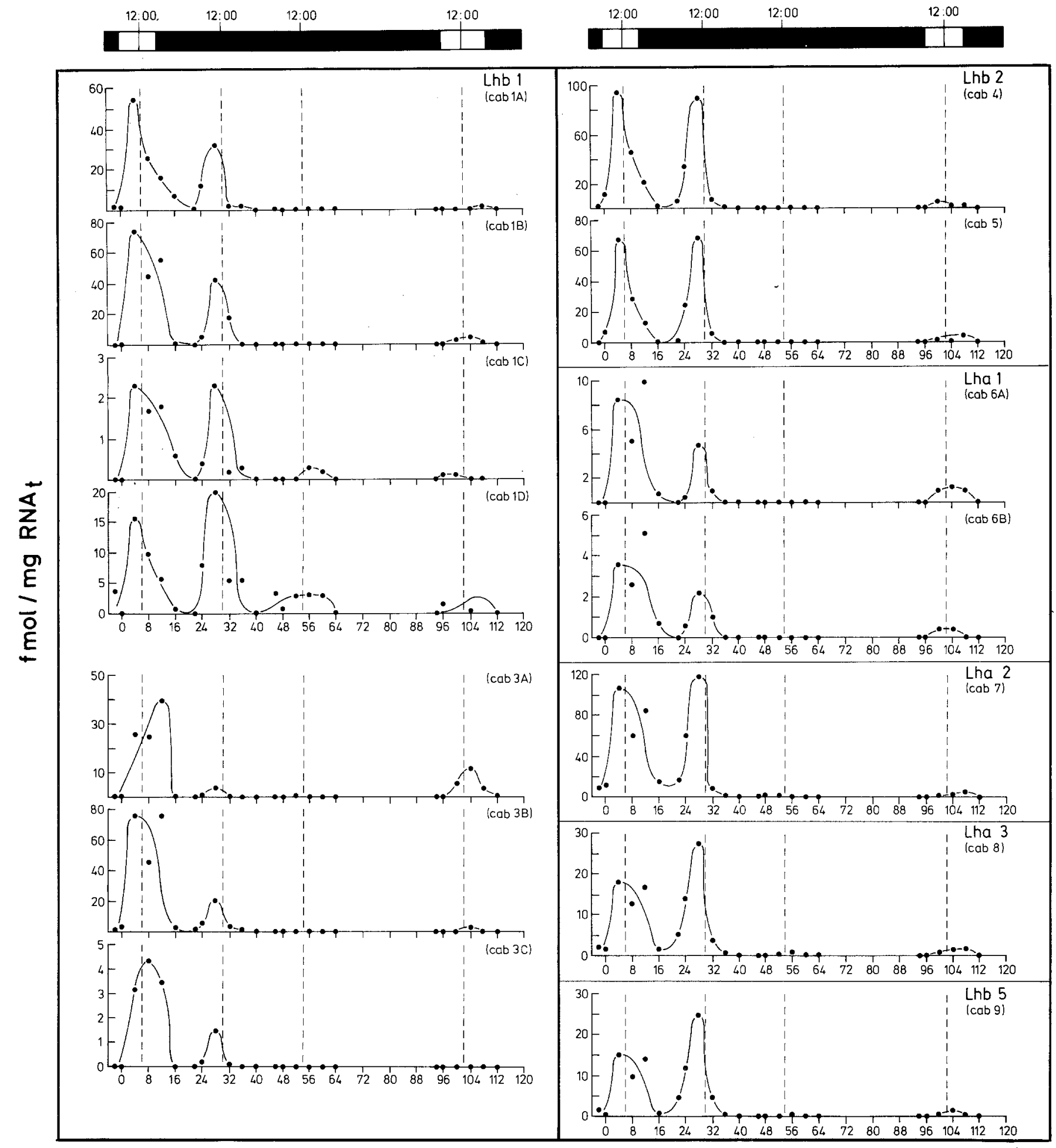

hours

Fig. 5. Circadian rhythms of individual Lhalb genes of L. esculentum in continous darkness. RNA was extracted from leaves of

fmol/mg total RNA. Genes encoding one type of LHC protein are shown together in sections. Dark and light phases are represented by filled and open bars, respectively. Zeitgeber time is presented and the time point of the first dark/light transition was

set as zero ual $L h a / b$ genes were calculated based on the primer extension analysis. The amount of individual Lha/b mRNA is given in 


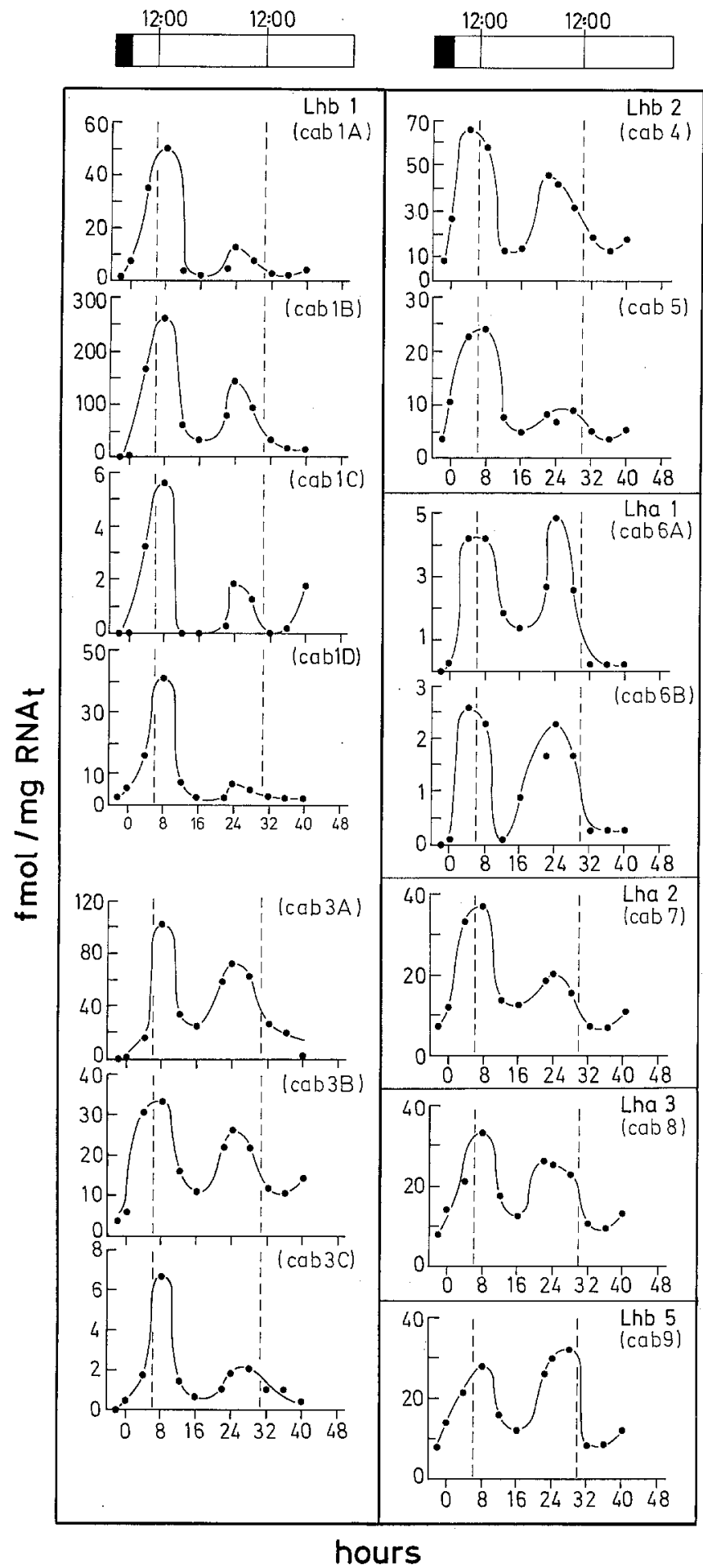

Fig. 6. Circadian rhythms of individual $L$ ha/ $b$ genes of $L$. esculentum in continuous light. RNA was extracted from 42-day-old tomato plants. Steady-state mRNA levels of the individual $L h a / b$ genes were calculated based on the primer extension analysis. The amount of individual $L h a / b$ mRNA is given in fmol/mg total RNA. Genes encoding one type of LHC protein are shown together in sections. Dark and light phases are represented by filled and open bars, respectively. Zeitgeber time is presented and the time point of the first dark/light transition was set as zero tion of this experiment is shown in Fig. 5. Amplitudes of at least $50 \mathrm{fmol} L h a / b$ mRNA per mg total RNA are reached by the genes $L h b 1 b, 1 f, 1 g, 2 a(c a b 1 B, 3 A$, $3 B, 4)$ and $\operatorname{Lha} 2(c a b 7)$. These five genes comprise between 60 and $70 \%$ of the total $L h a / b$ mRNA transcripts. The mRNA accumulation patterns of each individual $L h a / b$ gene were also followed in continuous darkness (Figs. 4 and 5) and continuous illumination (Fig. 6). Under these conditions all nineteen $L h a / b$ mRNA levels continue to oscillate. The period lengths are approximately $24 \mathrm{~h}$ in continuous darkness and vary between 16 and $20 \mathrm{~h}$ in continuous light, indicating that all $L h a / b$ genes examined are under the control of a circadian clock.

The circadian expression patterns of all $L h a / b$ genes examined, showed only minor differences in the amplitudes of the transcript levels. We note that the amplitudes of $L h b 1 a-1 d$ (cab 1A-1D) are high for the first day in darkness, while the amplitudes of Lhb1f-1h (cab $3 A-3 C$ ) are significantly reduced compared to the oscillation under light/dark conditions. The reverse result was observed in continuous illumination, where the amplitudes of $L h b 1 a-1 d(c a b 1 A-1 D)$ are more reduced than the amplitudes of $L h b 1 f-1 h(c a b 3 A-3 C)$. Another difference is that in continuous darkness $L h a / b$ mRNA levels decrease to almost undetectable levels during the subjective night phase, while elevated levels remain present during the subjective night phase during continuous illumination. Besides these fine discrepancies, different accumulation patterns are detected after 3 days in darkness followed by one dark/light transition; Lhb1d, if $(c a b 1 D, 3 A)$ and Lha1a, 4 (cab6A, 11) mRNA levels accumulate to detectable levels, while the residual $L h a / b$ gene mRNAs are almost undetectable.

\section{Discussion}

In this study the transcripts of the individual $L h a / b$ genes of L. esculentum were analysed. The mRNAs of all nineteen $L h a / b$ genes are expressed in the different green plant organs, indicating that a full complement of the mRNAs and their respective gene products are necessary for a functional photosynthetic apparatus. The accumulation of the individual $L h a / b$ mRNAs and the contribution to the total $L h a / b$ transcript level are different, namely $L h a 2(c a b 7)$ and $L h b 1 b, 1 f, 1 g, 2 a(c a b 1 B, 3 A$, $3 B, 4)$ are highly expressed, while the RNA products of the other twelve genes accumulate to low levels. The quantitative differences between the $L h a / b$ genes that are expressed in high and low amounts are prominent and this general pattern is present in all the different organs (Fig. 2). Exact quantitation of transcripts particularly of genes of a huge gene family as studied here is very difficult but the 'primer extension' method turned out to be quite a useful technique. However, it is worth mentioning that in a few cases the experimental error can be as much as $30 \%$ and deviations beyond the error bars cited in previously published data sometimes occurred, e.g. Lhb1f (cab3A) 8 versus $12 \%$ (previously) or $\operatorname{Lhb} 1 g$ (cab3B) 10 versus $30 \%$ (previously) 
(Piechulla et al. 1991). Our present stage of knowledge is documented in Fig. 2 and the discrepancies observed are most probably additive effects of the limits of reproducibility of the method and variations in the plant material and RNA preparations. In this context it is worth mentioning that oligonucleotides that bind to different positions in the mRNAs can result in different amounts of primer extended fragment (Piechulla et al. 1991). This effect is explained by incomplete binding due to structural hindrance. These and other methodological inadequacies may be the reason for the standard deviation of $20 \%$ obtained when a PCR technique was applied to quantitate Lha/b mRNA levels in Pisum sativum (White et al. 1992).

Besides the fact that the steady-state mRNA levels at noon vary significantly between the individual $L h a / b$ mRNAs, a general distribution pattern was observed within the different organs or after illumination with different light intensities and light qualities (Fig. 2). In addition, very similar diurnal and circadian expression patterns are observed for all $L h a / b$ genes (Figs. 4, 5 and 6). Based on these similarities, these data indicate a concerted expression of the $L h a / b$ genes. Only subtle differences primarily in the amplitude, were found between the mRNA accumulation patterns of different tomato $L h a / b$ genes, but no significant variations in the period lengths are apparent. In Arabidopsis thaliana, however, one $L h b 1$ gene $(c a b 1)$ of the three genes investigated exhibited little or no cycling of the mRNA level (Millar and Kay 1991). An interesting feature of circadian oscillations is the time point of $L h a / b$ mRNA accumulation. While in petunia the transcripts of all five genes examined start to increase about $6 \mathrm{~h}$ and reach $20-80 \%$ of the maximum level prior to the dark/light transition (Stayton et al. 1989), only two Lha/b genes (Lhb1 $a$ and $2 a$ ) in tomato show similar expression patterns (Figs. 4 and 5). These interspecific differences may be explained by different mechanisms regulating the transcription of the respective $L h a / b$ genes.

We conclude that the Lha/b genes from tomato and most probably also from other higher plants are under the control of a 'biological clock'. The diurnal and circadian Lha/b mRNA oscillations are most probably due to changes in transcriptional activity as demonstrated by Giuliano et al. (1988), Taylor (1989) and Meyer and Piechulla (unpublished results), but differential alterations in RNA stability may also play a role in some cases (Millar and Kay 1991; Meyer and Piechulla, unpublished results). Since the mRNAs of the $L h a / b$ genes exhibit circadian oscillations, it may be likely that a common cis- and/or trans-regulating factor is involved in expression of all these genes. A 'clock-responsive element' of $268 \mathrm{bp}$ length has only been defined in the $5^{\prime}$ flanking region of the wheat $L h b 1$ ( $c a b 1$ ) gene (Fejes et al. 1990), but no similarity to this fragment was detectable in any of seventeen analysed 5' flanking sequences of the tomato $L h a / b$ genes. In addition, the sequence comparison study of the tomato 5 -upstream sequences revealed no DNA motif present in all upstream regions (accept for the TATA- and CCAAT-box), which can be targeted by the same trans-acting factor leading to similar expression patterns (Piechulla et al. 1991). At present nothing is known about any trans-regulating factors that function at the $5^{\prime}$-upstream region of any $L h a / b$ gene from tomato. However, in other plant species, for example in tobacco, several proteins that bind to distinct 5 -upstream sequences of the Lhb1 ( $c a b E$ ) gene have been isolated and characterized (Schindler and Cashmore 1990). Nevertheless the specific functions of these DNA-binding proteins in vivo are presently unknown. Similarly, but even more complex, appear Pa results of in vitro protein-promoter DNA interactions analysed for the $r b c S$ gene family of tomato (Manzara et al. 1991). It is worthwhile mentioning that the five genes of the $r b c S$ gene family are, for example, differentially expressed in different organs (Sugita and Gruissem 1987) and therefore different DNA-motifs and DNA-binding proteins are expected. In contrast, based on the similarity of the expression patterns of the $L h a / b$ genes from tomato (present study) we either expect similar cis- and trans-regulating elements and signal transduction chains for each $L h a / b$ gene or, alternatively, different proteinpromoter interactions and signal transduction chains lead to the same expression patterns. It is expected that a comprehensive and detailed analysis of the cis- and trans-regulating elements of all tomato $L h a / b$ genes will give insight into the mechanism(s) co-ordinating the concerted expression of the $L h a / b$ gene family of tomato.

Acknowledgement. The authors thank Mrs. S. Hourticolon and Mr. $B$. Raufeisen for their preparation of the photographs and figures and Mrs. S. Voeckel and Mr. KH. Lange for cultivating the tomato plants. We thank Professor E. Schäfer for allowing us to illuminate etiolated seedlings under defined light qualities and for helpful discussions. This work was supported by a grant of the DFG to B.P. (Pi 153/2-4) and a fellowship of the Graduiertenförderung of the University of Göttingen to J.W.K.

\section{References}

Dean C, Favreau M, Dunsmuir P, Bedbrook J (1987) Confirmation of the relative expression levels of the Petunia (Mitchell) rbcS genes. Nucleic Acids Res 15:4655-4668

Fejes E, Pay A, Kanevsky I, Szell M, Adam E, Kay SA, Nagy F (1990) A 268 bp upstream sequence mediates the circadian clock-regulated transcription of the wheat $c a b-1$ gene in transgenic plants. Plant Mol Biol 15:921-932

Giuliano G, Pichersky E, Malik VS, Timko MP, Scolnik PA, Cashmore AR (1988) Light-entrained circadian clock controls transcription of several plant genes. Proc Natl Acad Sci USA 85:7089-7093

Green BR, Pichersky E, Kloppstech K (1991) Chlorophyll a/bbinding proteins: an extended family. Trends Biol Sci 16:180186

Jansson S, Pichersky E, Bassi R, Green BR, Ikeuchi M, Melis A, Simpson DJ, Spangfort M, Staehelin LA, Thornber JP (1992) A nomenclature for the genes encoding the chlorophyll a/b-binding proteins of higher plants. Plant Mol Biol Rep, 10:242-253

Kay SA, Millar AJ (1992) Circadian regulated $c a b$ gene expression in higher plants. In: Young $M$ (ed) The molecular biology of circadian rhythms. Marcel Dekker, New York

Kellmann JW, Pichersky E, Piechulla B (1990) Analysis of the diurnal expression patterns of the tomato chlorophyll $\mathrm{a} / \mathrm{b}$-binding protein genes. Influence of light and characterization of the gene family. Photochem Photobiol 52:35-41 
Kuhlemeier C, Green PJ, Chua NH (1987) Regulation of gene expression in higher plants. Annu Rev Plant Physiol 38:221257

Manzara T, Carrasco P, Gruissem W (1991) Developmental and organ-specific changes in promoter DNA-protein interactions in the tomato $r b c S$ gene family. Plant Cell 3:1305-1316

Meyer H, Thienel U, Piechulla B (1989) Molecular characterization of the diurnal/circadian expression of the chlorophyll a/b-binding proteins in leaves of tomato and other dicotyledonous and monocotyledonous plant species. Planta 180:5-15

Millar AJ, Kay SA (1991) Circadian control of $c a b$ gene transcription and mRNA accumulation in Arabidopsis. Plant Cell 3:541550

Mohr H, Drumm H, Schmidt R, Steinitz B (1979) The effect of light pretreatments on phytochrome-mediated induction of anthocyanin and of phenylalanine ammonia-lyase. Planta $146: 369-376$

Piechulla B, Riesselmann S (1990) Effect of temperature alterations on the diurnal expression pattern of the chlorophyll $\mathrm{a} / \mathrm{b}$ binding proteins in tomato seedlings. Plant Physiol 94:1903-1906

Piechulla B, Kellmann JW, Pichersky E, Schwartz E, Förster HH (1991) Determination of steady-state mRNA levels of individual chlorophyll $\mathrm{a} / \mathrm{b}$ binding protein genes of the tomato $c a b$ gene family. Mol Gen Genet 230:413-422

Schindler U, Cashmore AR (1990) Photoregulated gene expression may involve ubiquitous DNA binding proteins. EMBO J $9: 3415-3427$
Sheen JY, Bogorad L (1986) Differential expression of six lightharvesting chlorophyll $\mathrm{a} / \mathrm{b}$ binding protein genes in maize leaf cell types. Proc Natl Acad Sci USA 83:7811-7815

Stayton MM, Brosio P, Dunsmuir P (1989) Photosynthetic genes of Petunia (Mitchell) are differentially expressed during the diurnal cycle. Plant Physiol 89:776-782

Sugita M, Gruissem W (1987) Developmental, organ-specific, and light-dependent expression of the tomato ribulose-1,5-bisphosphate carboxylase small subunit gene family. Proc Natl Acad Sci USA 84:7104-7108

Tavladoraki P, Argyroudi-Akoyunoglou J (1989) Circadian rhythm and photochrome control of LHC-I gene transcription. FEBS Lett 255:305-308

Taylor WC (1989) Regulatory interactions between nuclear and plastid genomes. Annu Rev Plant Physiol Plant Mol Biol $40: 211-233$

Wehmeyer B, Cashmore AR, Schäfer E (1990) Photocontrol of the expression of genes encoding chlorophyll $\mathrm{a} / \mathrm{b}$ binding proteins and small subunit of ribulose-1,5-bisphosphate carboxylase in etiolated seedlings of Lycopersicon esculentum (L.) and Nicotiana tabacum (L.). Plant Physiol 93:990-997

White MJ, Fristensky BW, Falconet D, Childs LC, Watson JC, Alexander L, Roe BA, Thompson WF (1992) Expression of the chlorophyll a/b-protein multigene family in pea (Pisum sativum L.). Planta 188:190-198

Communicated by J. Schell 